\title{
Conceptual Usage of Systems Dynamics in Patients Rehabilitation Management
}

Assist. Prof. Dr. Tudor Irimiaș

Babeș-Bolyai University in Cluj-Napoca

Dr. Giuseppe Carbone

Laboratory of Robotics and Mechatronics, DiCEM, University of Cassino and South Latium

Prof. Dr. Adrian Pîslă

Technical University in Cluj-Napoca

Abstract

The essence of social sciences is well encompassed in Green's (2006) quote "People were created to be loved. Things were created to be used. The reason why the world is in chaos is because things are being loved and people are being used. " For this reason, social sciences are important, as major research paradigm on how and why individuals interrelate. The aim of the actual research is to look for a conceptual approach activity, as part of a larger project focused on individual rehabilitation. The brain is trained to react to the stimulus and command a behavior. The premise, for the considered approach, is understanding the social sciences as revealing the individuals interests for self conscience, well being and moral values and drawing the line to it's importance for governments authorities, policymakers or NGO's.

Keywords: conceptual, usage, systems, dynamics, patients, rehabilitation, management

\section{Introduction}

Needs and requirements for rehabilitation.

The need of assistance and rehabilitation is expected to increase in the near future in order to fulfill demands and requirements for physiotherapy and rehabilitation, (Simson 2005, Stein 2012). To provide a wider access to patients, especially due to aging populations and disperse geographic locations, the current demand for physiotherapy concerns the need to have user-sited therapy for motion training and rehabilitation with customized systems for specific patients.

A demand is already well understood as related to the demographic change. The OECD predicts an enlargement of the population of the over-65s to twice as many as the under-65s in 2050. Additionally, life expectation will increase. According to the European Commission, the population of the over-80s in the EU will grow from the current 21. 8 million to 61. 4 million in 2060. With this trend it is predicted that the number of therapists will decrease while the demand increases, thus the possibilities of having a personal therapy as today will be less available. To meet these changes, new ways of medical therapy will have to evolve. One of these kinds is user-sited therapy for motion training and rehabilitation.

The research is focused on the triggering factors that influence the people's behaviour and predisposition for change and their success in rehabilitation after accidents that may be caused by a variety of factors. As the behaviour of the individuals influences and changes our world, in a similar manner the environment (techno-natural and cultural-social and/or spiritual one) is influencing the individuals generally through standard ways like education, generation of the values map, professional competition, economical performance or as the actual ultimate goal the degree of satisfaction or happiness.

The conducted research is considered to belong to the change management methodology necessary for the permanent present duality: Homo Faber - Homo Sapiens. On one side the individual activity in direct correlation with its meanings is defined by the "owned tools" and on the other side the wish for understanding how to place the projection of the individual's self development is captured as a "desire support" defined by the "managerial capability".

Therefore, Engineering and Management approach and competences seem to be the right and important task force in promoting and enlarging the area of social-science, for competences oriented on the individuals well being and not only. In 
our era, the first (Homo Faber) dimension is strongly influenced by the evaluative trend of "Digital-age", where the wonder tools - the computers- in which mathematics, algorithms, electronics, physics and material science transform processes and knowledge in DDF (Digital Data Form). All this engineering process is leading to humans' new behaviour in creating models, scenarios and digital products for the everyday life aspects.

The second dimension (Homo sapiens) is represented by the capacity to organize structures of knowledge and use all the available DATA to create the most convenient environment combination (real + virtual) and forecasting the next status of an individual based on the actual behaviour structure and social living environment. This process may be considered to be based on the psycho-social development management where the technological culture and the change management can be used to create a guided impact on individual and collective well-being.

The individual's change is a result of the interaction between the micro and macro factors that at a certain scale of details enables the modeling of the "human subsystems" that are functioning in parallel: processes and functions. The implication of the induced change is the generation of a new function (that replaces a disappeared, or altered one) as an induced response to different social, politically correct integration, technological and economical external components.

The subjects for the research are considered as BIT's (Brain Injury Thrivers) as beneficiaries of much more customized functionality of the treatments and technologies implementations by considering the systems dynamics in the concept.

Any BIT destined activity is targeting the remained functionality potential of the system components and therefore can be treated as a system which flexibility is defined by the capacity of partial readjustment and "reprogramming". The components identification, correlation and adaptation through induced tasks must be a customized process where the most important factors are the trigerring ones.

When working with a system driven by fluxes, sensitive to trigering factors, a plausible way to get a defining conceptual edge for the change is similar to enclose its impact and effects upon the holistic vision of the change management, as Heda and Nagrath (2007) for a customized rehabilitation acyivity. The same opinion shares Holden (2008) through his statement: „Research on organizational change and innovation, technology implementation and macroergonomic redesign has converged on two important meta-principles for change management: adopting a systems approach and considering the dynamic properties of change."

The theory of systems dynamics was the starting point in generating a Dynamic Model of the Change, due to the overlapping of its scope with the present paradigm of change management: "the subject confronts with extreme complex matters, very dynamic or contains a large number of feedbacks. A model of the ...system dynamics focuses on the primary attributes of the system and allows encompassing of the variables with a high uncertainty level". (Thompson and Bank, 2010).

In the context of modeling the change management process, the system dynamics theory has created a suitable background for us to generate a tool for planning, integration and consolidation of the change through using the control of both scope and dimension of the change demand.

First we generate a short description of the elements of systems dynamics which characterize the change process in order to obtain the dynamic model of the change process. Second, the methodology of modeling the change is emerging from the perspective of the systems dynamics.

We are considering the Homer and Hirsch (2006) defined model, elaborated and generated through the theory of systems dynamics as "a set of algebraic differential equations, developed in a large spectrum of relevant measurements and empirical data. "Systems dynamics enables a set of tools that allows the change agent visualizing and processing the interaction of the elements of the analyzed system. Hence a deeper understanding of the system is created.

\section{Defining elements of systems dynamics}

As main instrument for visualize and analize the systems dynamics are the resources and flows diagrams to enable interdependencies and feedback through the accumulation of conventional accepted units whose value can raise or fall during different time frames depending on various factors of influence.

The resources and flows diagrams consist of the following structural elements: 
1. Resources ( $\square$ ) are accumulations of capabilities (tangible or intangible) concrete or abstract which can vary in time. The resources are the substantives of a system and they can only be modified through induced flows.

2. Flows $(-\bar{O} \rightarrow$ ) are actions or processes which acte over different system componnets to carry available resources for them, contributing at the altering of the dimension of the resources, through adding (inflow) or taking (outflow). A functionality quality is depending on a specific resource minimization or maximization. A flow is always a rate and is defined through units of considered resource per units of time. The flows are the verbs of a system and their names should always reflect this.

3. Convertors $(\bigcirc)$, ar parts of knowledge, carring data or information about the system which effects the flows or the value of another convertor.

4. Connectors ( $)$ helps to brings the data or information from an element of the system to another. The origin is the place where the information is taken and the final point is where the information is delivered.

The entire concept is based on the capacity to extend the model as much as our actual knowledge allow and to create correlations, interconnections, and scenarious generation for elements that may look so distant that are little considered or even ignored in the customization of the rehabilitation process

5. The limit of the system is represented like this: $Q$.

Any systems may come to an end. The end may be the reach of the maximum potential for desired resources, the saturation in resource accumulation due to known or anknown factors or even the unrecoverable colaps of the system.

The design process of resources and flow diagrams, together with the computerized modeling starts by identifying of the critical resources followed by naming the most important flows and finalized through the identification of the elements which alter the rates of the flows. This method of resources and flows was considered the most appropriate for the dynamic modeling of the change process because it suggests both the steps of the change management process and its dynamic potential.

The modeling of the change

Resources, rates of the flows and change convertors

As previous mentioned the actual research contributes to the conceptual approach of using a system dynamics management in the rehabilitation process.

The modeling and simulations capability is enabling a larger extension of the process customization and combine the main factors that are acting during the process time: social (family, friends, civil society...) politically correct integration (clinic, employer, gouvern, ...), technological (available devices, materials and technologies) and economical (private and societal capacity).

The scope of simulating the change management process is the potential estimation of the dimension of the expected change from the resources of change accumulation and determining the way of change development in a specific horizont of time.

For designing the simulation, the elements of The Dynamic Change Model (DCM) have been defined:

9 resources:

The Phisical capacity

The Phisical integrity

The Existing strategic functionality

The Awareness

The Availability of Integrated Methodology (AIM)

The Stability

The Stable elements

The Elementary needs

The Accumulated planned resources

16 rates of flows: 
The Decrease of the Change from the physical capacity

The Decrease of the Change from the physical integrity

The Physical capacity indicators impact over the needs

The Physical integrity indicators impact over the needs

The Decrease of the existing strategic functionality

The Needs increasing by adopting Change Indicators Values (CIV)

The Unplanned needs increasing

The Needs increasing due to stability rate

The Needs decreasing due to AIM

The Decrease of AIM due to apposed resistance to change

The Decrease of the AIM due to increase of stability

The Accumulated stability

The Accumulation of the planned change

The Decrease of the planned change

The Stability loss fraction

The Accumulated Planned Change

9 convertors:

The Rate of adoption initiative and needs

The Saturation impact of the needs change

The Rate of resistance to the AIM

The Rate of motivating the needs of the AIM

The Integration rate of the planned change

The Assimilation rate of physical capacity

The Altering rate of the physical integrity

The Tolerance at methodology deviations

The Strategic efficiency of the methodology

Considering the defining differential equations of the Dynamic Change Model and the causality diagrams, which put into light the relations and interactions of the mentioned resources with the other components of the model like convertors and rates of flows, a logic iterative scheme was built which consists of the following elements:

Table 1. The Elements of the Dynamic Change Model

\begin{tabular}{|l|l|l|l|}
\hline Notation & Abbreviation & Type & Interval/Value \\
\hline Time Units & TU & Variable with real values & {$[0,54]$} \\
\hline Change Units & $\mathrm{CU}$ & Variable with real values & {$[0,50]$} \\
\hline The time of the total simulation & {$[\mathrm{T}]$} & Total simulation time & $54 \mathrm{TU}$ \\
\hline The instantaneous time of the & {$[\mathrm{t}]$} & Real simulation time, TU Variable with real & {$[0,54]$} \\
\hline The time of one time step & {$[\mathrm{dt}]$} & TU interval & $0.25 \mathrm{TU}$ \\
\hline The physical capacity & {$[0]$} & Accumulation resource of CU & {$[0,20]$} \\
\hline The physical integrity & {$\left[0^{\prime}\right]$} & Accumulation resource of CU & {$[0,20]$} \\
\hline The Existing strategic & {$[1]$} & Accumulation resource of CU & {$[0,40]$} \\
\hline $\begin{array}{l}\text { The Decrease of the Existing } \\
\text { strategic functionality }\end{array}$ & {$\left[1^{\prime}\right]$} & $\begin{array}{l}\text { The transit time of the decrease of the } \\
\text { resource }\end{array}$ & 0.5 TU \\
\hline $\begin{array}{l}\text { The Physical capacity indicators } \\
\text { impact over the needs }\end{array}$ & {$[2]$} & Rate of flow CU / TU & {$[0,20] ; \mathrm{dt}$} \\
\hline $\begin{array}{l}\text { The Physical integrity indicators } \\
\text { impact over the needs }\end{array}$ & {$\left[2^{\prime}\right]$} & Rate of flow CU / TU & {$[0,20] ; \mathrm{dt}$} \\
\hline Awareness & {$[3]$} & Accumulation resource of TU & {$[0,40]$} \\
\hline Elementary needs & {$\left[3^{\prime}\right]$} & Accumulation resource of TU & {$[0,40]$} \\
\hline The Accumulation of planned & {$\left[3^{\prime \prime}\right]$} & Rate of flow CU / TU & {$[0,20] ; \mathrm{dt}$} \\
\hline
\end{tabular}




\begin{tabular}{|c|c|c|c|}
\hline $\begin{array}{l}\text { The Decrease of the planned } \\
\text { change }\end{array}$ & [3"'] & $\begin{array}{l}\text { The transit time of the decrease of the } \\
\text { resource }\end{array}$ & $0.25 \mathrm{TU}$ \\
\hline $\begin{array}{l}\text { The Needs increasing by } \\
\text { adopting Change Indicators }\end{array}$ & [4] & Rate of flow US/ TU & {$[0,20] ; \mathrm{dt}$} \\
\hline Unplanned needs increasing & [5] & Rate of flow CU / TU & {$[0,20] ; \mathrm{dt}$} \\
\hline Needs increasing due to stability & [6] & Rate of flow CU / TU & {$[0,20] ; \mathrm{dt}$} \\
\hline Needs decreasing due to AIM & [7] & Rate of flow CU / TU & {$[0,20] ; \mathrm{dt}$} \\
\hline The AlM & [8] & Accumulation resurce of $\mathrm{CU}$ & {$[0,40]$} \\
\hline $\begin{array}{l}\text { The Strategic efficiency of the } \\
\text { methodology }\end{array}$ & [9] & $\begin{array}{l}\text { Predefined variable after diagnosing the state } \\
\text { of the enterprise through The Scorecard of the }\end{array}$ & $(1 ; 2 ; 3 ; 4)$ \\
\hline $\begin{array}{l}\text { The Tolerance at methodology } \\
\text { deviations }\end{array}$ & [9'] & Predefined variable after diagnosing the state & $(1 ; 2 ; 3 ; 4)$ \\
\hline $\begin{array}{l}\text { Decrease of AlM due to apposed } \\
\text { resistance to change }\end{array}$ & [10] & Rate of flow CU / TU & {$[0,20] ; \mathrm{dt}$} \\
\hline $\begin{array}{l}\text { The Decrease of the AIM due to } \\
\text { increase of stability }\end{array}$ & [11] & Rate of flow CU / TU & {$[0,20] ; \mathrm{dt}$} \\
\hline The Accumulated stability & [12] & Accumulation resource of US & {$[0,40]$} \\
\hline The Stability loss fraction & [12'] & Leakage fraction & 0.193 \\
\hline $\begin{array}{l}\text { The Decrease of the change from } \\
\text { the physical capacity }\end{array}$ & [13] & Rate of flow CU / TU & {$[0,20] ; \mathrm{dt}$} \\
\hline $\begin{array}{l}\text { The Decrease of the change from } \\
\text { the physical integrity }\end{array}$ & [14] & Rate of flow CU / TU & {$[0,20] ; \mathrm{dt}$} \\
\hline $\begin{array}{l}\text { Rate of adoption initiative and } \\
\text { needs }\end{array}$ & [15] & Variable with real values & {$[0,1]$} \\
\hline $\begin{array}{l}\text { The Saturation impact of the } \\
\text { needs change }\end{array}$ & [16] & Real variable represented as function of [1] & {$[0,1]$} \\
\hline Rate of resistance to the AlM & [17] & Real variable represented as function of [9] & $(0.1 ; 0.2 ; 0.3$ \\
\hline $\begin{array}{l}\text { Rate of motivating the needs of } \\
\text { the AIM }\end{array}$ & [18] & $\begin{array}{l}\text { Real variable represented as function of [19] } \\
\text { and [17] }\end{array}$ & {$[0,1]$} \\
\hline $\begin{array}{l}\text { The Integration rate of the } \\
\text { planned change }\end{array}$ & [19] & Real variable represented as function of [9'] & $\begin{array}{l}\text { (0. 55;0.7;0. } \\
85 ; 1)\end{array}$ \\
\hline The Stable elements & {$[20]$} & Accumulation resource of $\mathrm{CU}$ & {$[0,40]$} \\
\hline The Accumulated stability & {$\left[20^{\prime}\right]$} & Rate of flow CU / TU & {$[0,20] ; \mathrm{dt}$} \\
\hline Accumulated planned resources & [20"] & Accumulated resource of US & {$[0,40]$} \\
\hline The Accumulated planned & [20"'] & Rate of flow CU / TU & {$[0,20] ; \mathrm{dt}$} \\
\hline $\begin{array}{l}\text { The Assimilation rate of physical } \\
\text { capacity }\end{array}$ & [21] & Real variable represented as function of $[0]$ & {$[0,1]$} \\
\hline $\begin{array}{l}\text { The Altering rate of the physical } \\
\text { integrity }\end{array}$ & [22] & Real variable represented as function of [0'] & {$[0,1]$} \\
\hline
\end{tabular}

The resources of the DCM (Dynamic Change Model) tend to enclose change as a quantity of social, politically correct integration, technological and economical elements which combined, influence a need of resources in order to plan, integrate and consolidate the change. The needed resources are used as the function of the change quantity and so variations of the resources types in the different stages of the administration process can be observed and consulted. This model enables an overall image to the change agent of what is happening, where is it happening, and what, when and how is it to be done.

Considering the elements mentioned above, the logic diagram of the Dynamic Change Model which describes the 
conditions and the limits of the process is depicted:

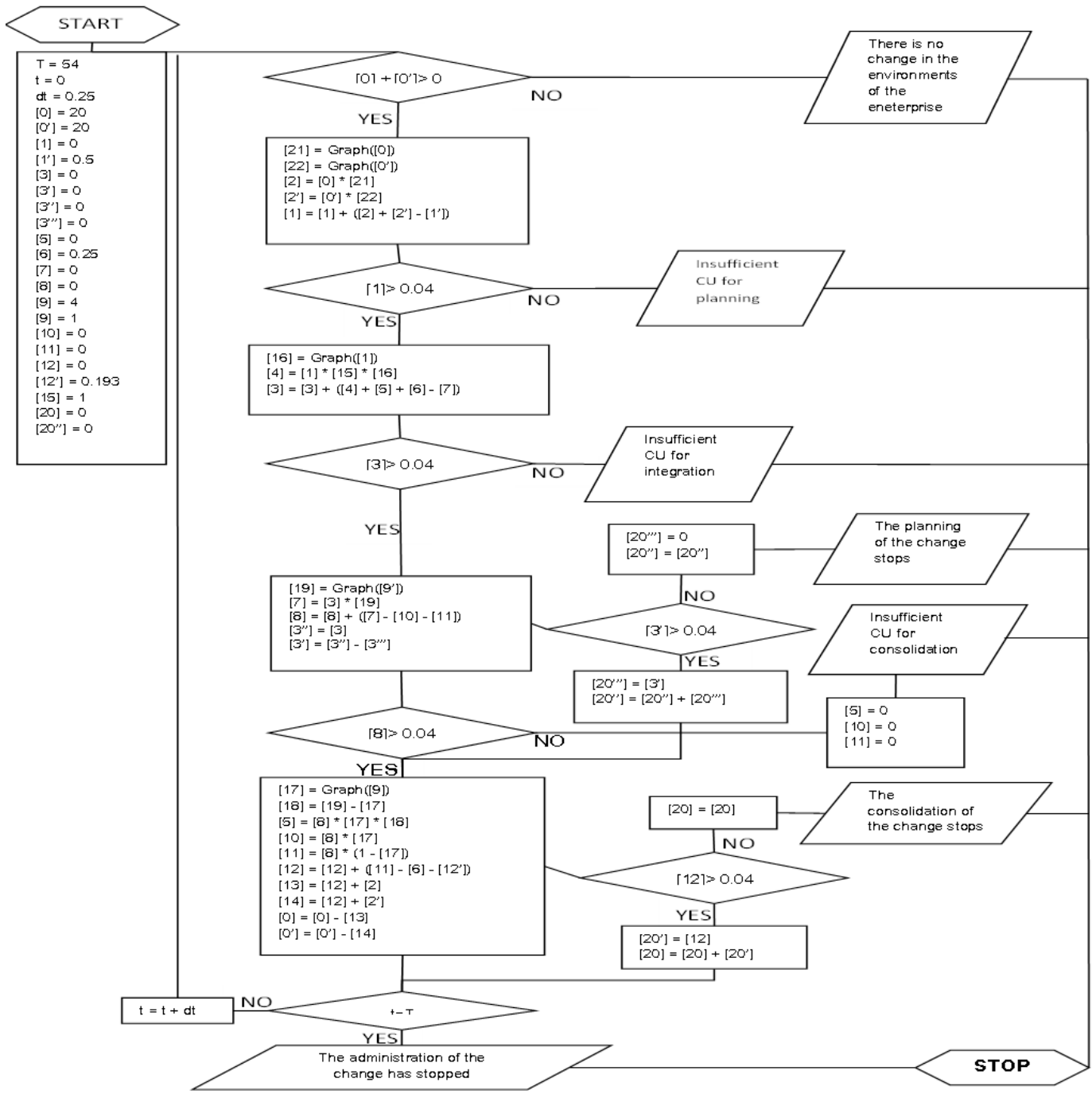

\section{Diagram 1. The Logic diagram of the Dynamic Change Model}

It is to mention that the conceptual notations of the change process are based upon some vast theoretical and empirical data processing. The representing of the change flows in this manner is a concept of novelty and interdisciplinary approach both the engineering point of view and the managerial one. This way of enclosing the change management process through the theory of systemic thinking enhances the prospects for more effective integration to the continuous and rapid changes.

Hence, the use of technology though the computerized simulation of the change process eases the managerial activities and practices providing a favorable environment of managerial technical and communicational growth. The dynamic modeling of the change offers not only guidelines of respecting and applying policies and deadlines but also it provides the control function without which the consolidation of the change would be futile.

\section{Premises of simulating the dynamics of the change}


In building the Dynamic Model of the Change (DCM), following considerations are to be taken into account:

\section{Change has a certain degree of incertitude which derives from its complex nature.}

This is a result of the fact that change occurs and interacts from and on four separate environments (social, internal politics, technological and economical). Therefore, it can be concluded that two of the most important characteristics of the change are: change has an iterative character and it requests continuous adjustment;

The presented modeling and simulation concept follows the principle of the Kemmis and McTaggart's (2000) Action Research Spiral, whilst the administration of the change is considered a continuous and endless process of adjusting the present functionality to the strategic one. It is considered the fact that if the decision of adopting a change is taken, there is no turning back;

The composition elements can be partially represented through the change indicators;

Change management implies two different kinds of control: of the scope and of the dimension. Considering the scope means in change management, the strategically approach which allows the change agent maintaining the administration plan and meeting the imposed or proposed deadlines.

The scopes of the DCM are:

Permitting a dynamic modeling environment through considering the strategy of the enterprise from a normative point of view and which allows the understanding of the change process through its steps;

The presentation of a proactive mechanism of command and control of the change;

A change management model based on systems dynamics which facilitates the viewing of the process and offers support during its side activities of detection, planning, implementing, consolidating and control of the change.

The dynamic system, which allows visualization of the change management process, is built on the following principles:

The resources characterize the "quantity" of change which has to be administrated;

With this scope, the "quantity of change" - QC, will be evaluated by the change agent through considering all the steps of the process and allocating the degree of the needed resources to make the change happen.

\section{$Q C=(H R+F R+S I R+H I R) / T R$}

where every one of this resource types can take values from this aggregate: $\{1,2,3,4,5\}$

HR: Human Resources

FR: Financial Resources

SIR: Soft Infrastructural Resources

EIR: Equipment Infrastructural Resources

TR: Time Resources

Explanation: if the numerator of the fraction is constant than the quantity of the change grows with the decrease of the available execution time. If the execution time is constant, the quantity of the change grows with the quantity of needed allocated resources:

$$
C Q_{\text {max }}=\left(H R_{\text {max }}+F R_{\text {max }}+S I R_{\text {max }}+H I R_{\text {max }}\right) / T R_{\text {min }} S_{i C Q_{\text {min }}}=\left(H R_{\text {min }}+F R_{\text {min }}+S I R_{\text {min }}++H I R_{\text {min }}\right) / T R_{\text {max }}
$$

The flows are built and influenced by specific change indicators depending of the change quantity and the needed or imposed administration time resource

The convectors modify the flow rates of the change quantity both through the influence of the factors of the physical integrity but also through those from the physical capacity. 
Considering these elements of composition, the map of the DCM takes the following shape:

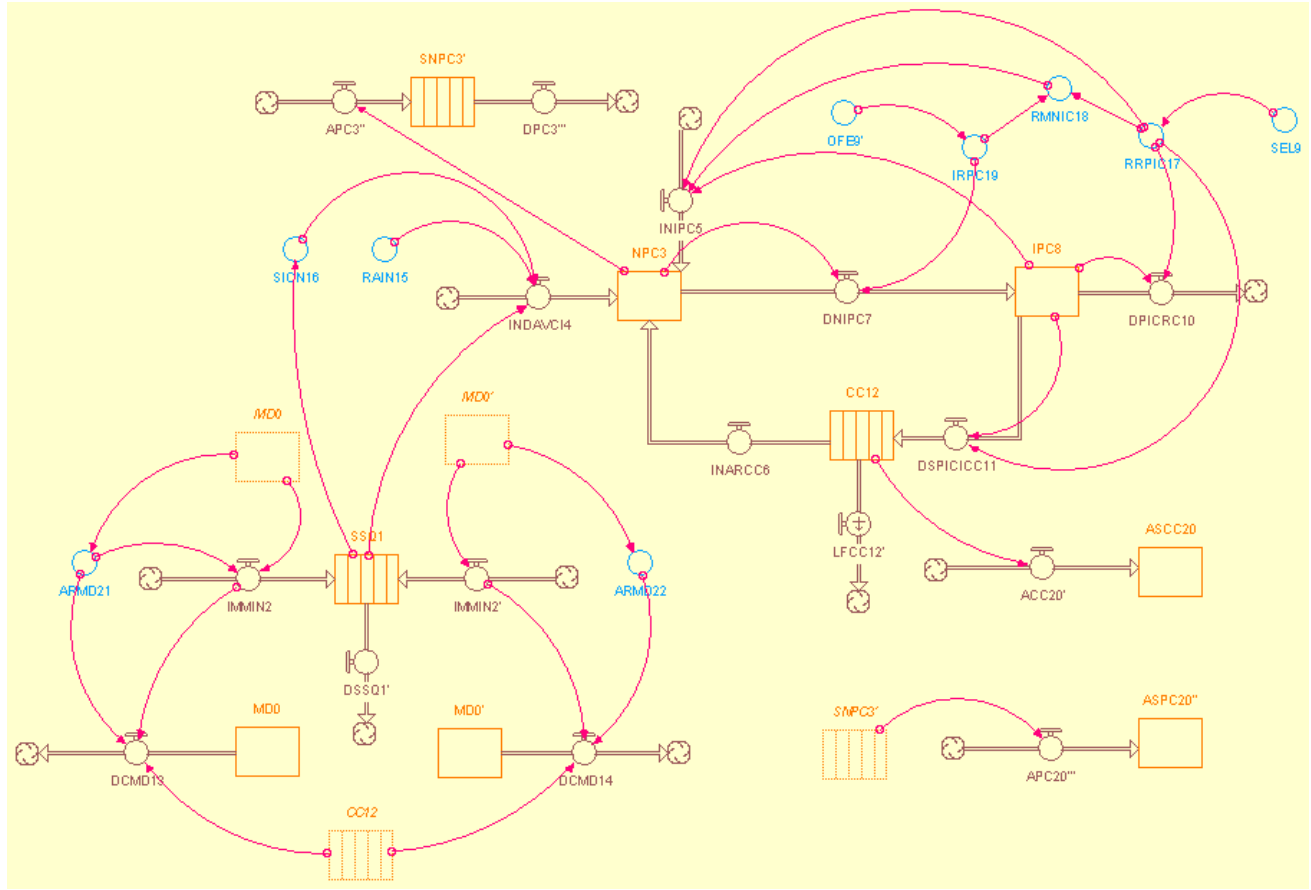

Diagram 2. The Dynamic Change Model Map

As a result of the DCM, generated through the software iThink ${ }^{1}$, a set of elements were observed which are further on considered as inputs and that enable the adjustment of the change quantity as follows:

The Rate of adoption initiative and Needs ${ }^{15}=\mathrm{X}_{15}$, established after the decision of the physicians board to adopt the quantity of the change after consulting the change indicators which populate the columns "real value" and "desired value" from the SCC; it takes values between 0 and 1 and it is measured by available resources for the consolidation of the planned change.

The Saturation Impact of the needs change ${ }^{16}=\mathrm{X}_{16}$, are data generated automatically by the graphic function of The Strategic functionality ${ }^{1}$ and it expresses the grade of openness for the change in general. $X_{16}$ takes values in the interval $[0$, 1] and denotes the capacity to materialize a change necessity through its planning and later consolidation.

The Strategic efficiency of the methodology ${ }^{9}$ determines the rate of resistance to the planned integrated change $Y_{17}$ though the GRAPH (The Strategic efficiency of the methodology) as follows: (inexistent $\left.{ }^{1}, 0.4\right)$, (small $\left.{ }^{2}, 0.3\right)$, (medium ${ }^{3}, 0$. 2), (high 4 , 0. 01).

The Tolerance at the methodology deviation ${ }^{9}$, determines the rate of integration of the planned change $Y_{19}$ through the GRAPH (The Tolerance at the methodology deviation) as follows: (flexible ${ }^{1}, 1$ ), (relatively flexible ${ }^{2}, 0.85$ ), (little flexible ${ }^{3}, 0$. 7), (inflexible $\left.{ }^{4}, 0.55\right)$.

The change quantity from The Physical capacity $0=\mathbf{X}_{0}$, where $\mathrm{x}$ belongs to $[0,1]$ and is established by the change specialist as a result of a discussion with the physicians board, depending on the necessary resources for the consolidation of the planned change.

${ }^{1} \mathrm{http}: / / w w w . i s e e s y s t e m s . c o m / S o f t w a r e s / B u s i n e s s / i t h i n k S o f t w a r e . a s p x$ 
The change quantity from The Pysical integrity $0^{\prime}=\mathrm{X}_{0^{\prime}}$, where $\mathrm{x}$ belongs to $[0,1]$ and is established by the, change specialist as a result of a discussion with the physicians board, depending on the necessary resources for the consolidation of the planned change.

\section{Conclusions and implication of the change administration from an enterprise.}

The Accumulated Needs of the Stability (named SASC ${ }^{20}$ ) has to be discussed depending on The Accumulation resources of the Planned Change (named SASP20); both resources are output data. Taking this into consideration following adjustment propositions and conclusions can be carried out whilst analyzing $\mathbf{X}_{15}, \mathbf{X}_{16}, \mathbf{Y}_{17}, \mathbf{Y}_{19}, \mathbf{X}_{21}, \mathbf{X}_{22}$ :

The calculation of the correlation coefficient for the values of $S A S C^{20}$ and $S A S P^{20}$ "has given a strong relationship ( 1) of the evolution in time of this two resources through considering the permanent condition SASP > SASC.

The necessary time for the change administration shrinks with the growth of the values for Strategic efficiency of the methodology and the decrease of the values of the Tolerance at the methodology deviations. This will be established through dividing the interval $[0,54]$ of time units through the number of hours, days, months needed for consolidating the planned change. So the change quantity of the needed planned change will be established in order to induce a potential consolidated change.

The simulation with maximal input data for $\mathbf{X}_{15}, \mathbf{X}_{16}, \mathbf{Y}_{17}, \mathbf{Y}_{19}, \mathbf{X}_{0}$ and $\mathbf{X}_{0}$, has a $100 \%$ accumulation of change in The Stable elements ${ }^{20}$.

In the case of the simulation with minimal input values for the $Y_{17}$ and $Y_{19}$ holding the premise of maximum change occurrence, The Stable elements ${ }^{20}$ has an accumulation of $28.25 \%$. From this can be concluded that The Strategic efficiency of the methodology ${ }^{9}$ and The Tolerance at methodology deviations ${ }^{9}$ are very important during executing change management. DCM delivers, after the simulation of the administration process, the change quantity which is to be consolidated in a specific period of time.

After the simulation one can make valuable recommendations over:

The execution time of the change and the change quantity which has to be planned in order to report an efficient consolidation.

Which composition elements can be improved?

The potential of consolidation of the planned change

The degree of resistance to change

The possibility of improving the capacity of assimilating and adapting to the change.

Acknowledgement

This paper was published with the support of the MNE - NASRI Intermediary Body for Research, through the Competitiveness Operational Programme 2014-2020, Priority Axis 1, Action 1. 1. 4, Project AgeWell, ID P_37_215, My SMIS Code 103415, Contract number 20/01. 09. 2016.

\section{References}

[1] Bisson, P., Stephenson, E. and Viguerie S. P (2010), "Global forces: An introduction", McKinsey Quarterly, June 2010.

[2] URL: http://www. mckinseyquarterly. com/Global_forces_An_introduction_2625 [accessed 10 Oct. 2011]

[3] Green, J. (2006). Looking for Alaska. Penguin Young Readers Group. ISBN 9780142402511.

[4] Heda, A. and Nagrath, A. (2007), Dimensions and Components for Organization Change Management - Part One, created: 07 September 2007, 
[5] URL: http://www. sdn. sap. com/irj/sdn [accessed 10 Oct. 2011]

[6] Holden, R. J. et al. (2008), "A change management framework for macroergonomic field research", Applied Ergonomics, Vol. 39, Pg. 459-474.

[7] Homer, J. B., Hirsch, G. B. (2006), „System dynamics modelingfor public health: background and opportunities”, American Journal of Public Health, vol. 96, nr. 3, Pg. 452-458.

[8] Irimiaş, T. and Pîslă, A. (2009) „The Presence of Change Management in the System Management Processes”, Industrial Engineering Journal RECENT, Vol. 10 (2009), No. 3 (27), ISSN 1582-0246, Pg. 313-316., 25-26 November, Braşov, Romania.

[9] Irimiaş, T. and Pîslă, A. (2010) „Change Management in Industrial Management”, 1st RMEE Management Conference: Twenty Years After - How Management Theory Works, The 1st RMEE Management Conference Proceedings, Pg. 261-270, 16-18 September, Technical University of Cluj-Napoca, Romania.

[10] Kemmis, S., \& McTaggart, R. (2000). Participatory action research. In N. Denzin \& Y. Lincoln (Eds. ), Handbook of qualitative research (2nd ed., pp. 567-605). Thousand Oaks, CA: Sage.

[11] Major, K. A., Major, Z. Z., Carbone, G., Pisla, A., Vaida, C., Gherman, B., Pisla, D. L., "Ranges of motion as basis for robot-assisted post-stroke rehabilitation. " HVM Bioflux 2016;8 (4):192-196.

[12] Tako, A. A. and Robinson, S. (2010), "Model development in discrete-event simulation and system dynamics: An empirical study of expert modelers", European Journal of Operational Research, Vol. 207 (2010), No. 2, Pg. 784-794.

[13] Thompson, B. P. and Bank, L. C. (2010), "Use of system dynamics as a decision-making tool in building design and operation", in Building and Environment, No. 45, Pg. 1006-1015.

[14] Simpson, R. C., "Smart wheelchairs: A literature review", J Rehabilitation Res Dev. 2005 Jul-Aug; 42 (4):42336. Review. PubMed PMID: 16320139.

[15] Stein, J., "Robotics in Rehabilitation: Technology as Destiny", American Journal of Physical Medicine \& Rehabilitation. 91 (11) (Supplement 3):S199-S203, November 2012. 